\title{
Correction to: A protocol for automated timber species identification using metabolome profiling
}

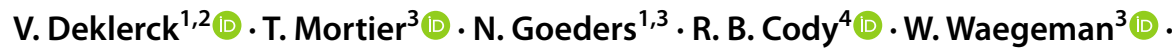

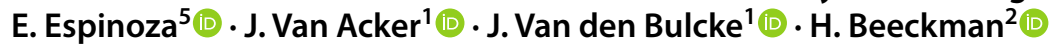

Published online: 19 July 2021

๑) Springer-Verlag GmbH Germany, part of Springer Nature 2021

\section{Correction to: Wood Science and Technology (2019) 53:953-965 https://doi.org/10.1007/s00226-019-01111-1}

Unfortunately, in the published version, the fourth paragraph under the heading Introduction, text phrase "The Entandrophragma species, together with the Swietenia's and Khaya species, are generally referred to as the mahoganies or the acajous from Africa (Beeckman 2003; Kasongo et al. 2019).” contains an error.

This text phrase needs to be replaced with the following sentence: "The Khaya species are generally referred to as the mahoganies or the acajous from Africa (Beeckman 2003; Kasongo et al. 2019). The Swietenia species are referred to as the American mahogany, and these are sometimes sold as "mahogany" together with Khaya and Entandrophragma species."

The author regrets for the inconvenience caused.

Publisher's Note Springer Nature remains neutral with regard to jurisdictional claims in published maps and institutional affiliations.

The original article can be found online at https://doi.org/10.1007/s00226-019-01111-1.

V. Deklerck

victor.deklerck@ugent.be

1 UGent-Woodlab, Laboratory of Wood Technology, Department of Environment, Faculty of Bioscience Engineering, Ghent University, Coupure Links 653, 9000 Ghent, Belgium

2 Service of Wood Biology, Royal Museum for Central Africa (RMCA), Leuvensesteenweg 13, 3080 Tervuren, Belgium

3 Department of Data Analysis and Mathematical Modelling, Ghent University, Coupure Links 653, 9000 Ghent, Belgium

4 JEOL USA, Inc., Peabody, MA 01960, USA

5 U.S. National Fish and Wildlife Forensic Laboratory, 1490 East Main Street, Ashland, OR, USA 